\title{
Two Layers of Synaptic Processing by Principal Neurons in Piriform Cortex
}

\author{
Norimitsu Suzuki and John M. Bekkers \\ Department of Neuroscience, The John Curtin School of Medical Research, The Australian National University, Canberra, Australian Capital Territory 0200, \\ Australia
}

The primary olfactory (or piriform) cortex is a trilaminar paleocortex that is thought to construct unified "odor images" from the odor components identified by the olfactory bulb. How the piriform cortex (PC) accomplishes this sophisticated synthetic task, despite its relatively simple architecture, is unknown. Here we used in vitro patch-clamp recordings from acute slices of the anterior PC of mice to identify microcircuits involved in excitatory synaptic processing. Cluster analysis confirmed the presence of two prominent classes of glutamatergic principal cells in the main input layer (layer II) of the PC: semilunar (SL) cells and superficial pyramidal (SP) cells. SL cells received stronger afferent excitatory input from the olfactory bulb, on average, than did SP cells. This was due to the larger mean strength of single-fiber afferents onto SL cells. In contrast, SP cells received stronger associational (intracortical) excitatory inputs, most likely due to their more extensive dendritic trees within the associational layers. Tissue-cut experiments and dual recordings from SL and SP cells in disinhibited slices were consistent with the distinctive patterns of connectivity of these two cell classes. Our findings suggest that the anterior PC employs at least two layers of excitatory synaptic processing: one involving strong afferent inputs onto SL cells, and another involving strong intracortical inputs onto SP cells. This architecture may allow the PC to sequentially process olfactory information within segregated subcircuits.

\section{Introduction}

Sensory processing is a complex process that involves distinct levels of coding, typically ranging from simple primitives at the level of receptor cells (e.g., saltiness, light intensity) to an elaborated percept at the level of the cortex (e.g., flavor, a visual scene). In seeking to understand sensory processing, study of the olfactory system offers a number of advantages. One advantage is that only a few synaptic layers interpose between odorant detectors in the periphery and high-level representations of odor space in the brain (Laurent, 2002). For example, in mammals the primary olfactory (piriform) cortex is thought to perform a high-level synthetic role, yet it is only two synapses removed from the olfactory receptor neurons in the nose (Neville and Haberly, 2004). For these and other reasons the piriform cortex $(\mathrm{PC})$ is attracting increasing attention as a promising model system for the study of sensory processing and integration (Suzuki and Bekkers, 2006; Barnes et al., 2008; Poo and Isaacson, 2009; Stettler and Axel, 2009; Isaacson, 2010; Stokes and Isaacson, 2010; Suzuki and Bekkers, 2010b; Wilson, 2010).

One strategy for studying the PC is to take a bottom-up cellphysiological approach, by first characterizing the major classes

\footnotetext{
Received 0ct. 15, 2010; revised Nov. 30, 2010; accepted Dec. 9, 2010.

This work was supported by Project Grants 224240, 471413, and 585462 from the National Health and Medical Research Council of Australia to J.M.B.

Correspondence should be addressed to John M. Bekkers, Department of Neuroscience, The John Curtin School of Medical Research, Building 131, The Australian National University, Canberra, ACT 0200, Australia. E-mail: John.Bekkers@anu.edu.au.

DOI:10.1523/JNEUROSCI.5430-10.2011

Copyright $\odot 2011$ the authors $\quad 0270-6474 / 11 / 312156-11 \$ 15.00 / 0$
}

of neurons and the microcircuits in which they are embedded. This approach has so far identified, for example, classes of glutamate-releasing principal neurons (Franks and Isaacson, 2006; Suzuki and Bekkers, 2006), their dendritic properties (Bathellier et al., 2009), circuits and synaptic plasticity (Franks and Isaacson, 2005; Poo and Isaacson, 2007; Johenning et al., 2009), and classes of GABA-releasing interneurons and their circuits (Young and Sun, 2009; Stokes and Isaacson, 2010; Suzuki and Bekkers, 2010a,b). We have previously reported that the main input layer of the PC, layer II, contains two functionally distinctive kinds of principal neurons, semilunar (SL) and superficial pyramidal (SP) cells (Suzuki and Bekkers, 2006). Here, we extend those earlier studies by more rigorously segregating SL and SP cells, and also by examining the properties of the microcircuits in which these cells function. Our findings further highlight the likely distinctive roles of SL and SP cells in olfactory processing.

Franks and Isaacson (2006) have reported that layer II/III pyramidal cells in the PC often receive powerful single-fiber afferent inputs from mitral/tufted $(\mathrm{M} / \mathrm{T})$ cells in the olfactory bulb, making it possible for coincident input from just a few $\mathrm{M} / \mathrm{T}$ cells to drive spiking in cortical pyramidal cells. Their finding allowed them to draw implications for olfactory coding in the PC. Here, we show that principal cells in the PC do, indeed, receive powerful single-fiber afferent inputs, but these are selectively targeted to SL cells. We also show that SP cells preferentially receive powerful intracortical (associational) excitatory inputs. Hence, SL and SP cells participate in two distinctive circuits, the former specializing in afferent processing, the latter in intracortical processing. 


\section{Materials and Methods}

Slice preparation. Experiments used acute brain slices (300 $\mu \mathrm{m}$ thick) prepared from the anterior PC of C57BL/6J mice of either sex (18-25 d old). The anterior PC was defined as that part of the piriform cortex anterior to the caudal limit of the lateral olfactory tract (LOT) (Neville and Haberly, 2004). In most cases coronal sections of the anterior PC were used, but in some cases sagittal slices containing the LOT were prepared (see Figs. 4, 6). Standard methods of slice preparation were used (Suzuki and Bekkers, 2006, 2010b). Briefly, mice were deeply anesthetized with isoflurane ( $2 \%$ in oxygen), then rapidly decapitated using procedures approved by the Animal Experimentation Ethics Committee of the Australian National University. Slices were prepared using a vibrating slicer (Campden Instruments) under ice-cold cutting solution, comprising (in mM) $125 \mathrm{NaCl}, 3 \mathrm{KCl}, 0.5 \mathrm{CaCl}_{2}, 6 \mathrm{MgCl}_{2}, 25 \mathrm{NaHCO}_{3}, 1.25 \mathrm{NaH}_{2} \mathrm{PO}_{4}$, and 10 glucose (osmolarity $305 \mathrm{mOs} / \mathrm{kg}$ ), bubbled with $5 \% \mathrm{CO}_{2} / 95 \% \mathrm{O}_{2}$ (carbogen). The slices were incubated for $1 \mathrm{~h}$ at $35^{\circ} \mathrm{C}$ in a holding chamber containing carbogen-bubbled artificial CSF (ACSF; composition below), and were then held at room temperature until required.

Electrophysiology. Standard infrared-enhanced videomicroscopy techniques were used to make visualized whole-cell patch-clamp recordings from glutamatergic principal neurons in layer II of the PC (Suzuki and Bekkers, 2006). In dual recording experiments (see Fig. 3), SL and SP cells were selected such that both somata lay on an imaginary line drawn perpendicular to the borders of layer II and immediately below the LOT. Identification of SL and SP cells was confirmed by measuring their distinctive passive and spiking properties (Suzuki and Bekkers, 2006) and by recovering each cell for morphological reconstruction (details below). GABA-releasing interneurons, which were occasionally encountered and identified by their characteristic passive and firing properties (Suzuki and Bekkers, 2010b), were discarded.

Slices were continuously superfused $(2-3 \mathrm{ml} / \mathrm{min})$ with ACSF comprising (in mM) $125 \mathrm{NaCl}, 3 \mathrm{KCl}, 2 \mathrm{CaCl}_{2}, 1 \mathrm{MgCl}_{2}, 25 \mathrm{NaHCO}_{3}, 1.25$ $\mathrm{NaH}_{2} \mathrm{PO}_{4}$, and 25 glucose $(310 \mathrm{mOs} / \mathrm{kg})$, bubbled with $5 \% \mathrm{CO}_{2} / 95 \% \mathrm{O}_{2}$ (carbogen) and maintained at $33-35^{\circ} \mathrm{C}$. Unless stated otherwise, the ACSF also contained picrotoxin $(100 \mu \mathrm{M})$ to block $\mathrm{GABA}_{\mathrm{A}}$ receptormediated inhibitory postsynaptic responses. For the synaptic train experiments (see Fig. 8), the ACSF contained D-2-amino-5-phosphonovaleric acid (D-APV, $50 \mu \mathrm{M}$; Tocris Bioscience) plus a low concentration $(1 \mu \mathrm{M})$ of 6,7-dinitroquinoxaline-2,3-dione (DNQX; Tocris Bioscience) to partially block EPSCs, minimizing polysynaptic excitation. For currentclamp recordings, patch electrodes had resistances of 6-10 $\mathrm{M} \Omega$ when filled with internal solution containing (in $\mathrm{mM}$ ) $135 \mathrm{KMeSO}_{4}, 7 \mathrm{NaCl}, 0.1$ EGTA, $2 \mathrm{Na}_{2} \mathrm{ATP}, 2 \mathrm{MgCl}_{2}, 0.3 \mathrm{GTP}, 10$ HEPES at $\mathrm{pH}$ 7.2, supplemented with $0.2-0.4 \%$ biocytin $(295-300 \mathrm{mOs} / \mathrm{kg})$. For voltage-clamp recordings, $135 \mathrm{~mm}$ Cs methane sulfonate replaced the $\mathrm{KMeSO}_{4}$, and electrodes had resistances of 4-7 M $\Omega$. Unless stated otherwise, all compounds were obtained from Sigma-Aldrich. For consistency with previous work (Suzuki and Bekkers, 2006), voltages have not been corrected for the junction potential, measured to be $-7 \mathrm{mV}$ for these solutions.

Data were acquired using a Multiclamp 700A amplifier (Molecular Devices). For current-clamp recordings, the cell was allowed to remain at its resting membrane potential $[\sim-69 \mathrm{mV}$ for SL cells, $\sim-75 \mathrm{mV}$ for SP cells (Suzuki and Bekkers, 2006)]. Families of current steps (duration 500 ms; amplitudes $-120 \mathrm{pA}$ to $500-2000 \mathrm{pA}$ in $10-40 \mathrm{pA}$ increments) were applied to identify the firing pattern. Bridge balance and capacitance neutralization were carefully adjusted and checked for stability. For voltage-clamp recordings, the soma was held at $-70 \mathrm{mV}$. Series resistance was monitored for stability but series resistance compensation was not used. Voltage or current traces were filtered at $10 \mathrm{kHz}$ and digitized at 20 or $50 \mathrm{kHz}$ by an ITC-18 interface (Instrutech/HEKA) under the control of Axograph (Axograph Scientific).

Focal extracellular synaptic stimulation was done using a custom-built isolated stimulator that delivered a $100-\mu$ s-long constant current pulse with an adjustable amplitude. Stimuli were applied at 10 or $15 \mathrm{~s}$ intervals. The stimulating electrode was constructed from a patch electrode (tip diameter $\sim 5 \mu \mathrm{m}$ ) filled with $1 \mathrm{M} \mathrm{NaCl}$ and coated with electrically conductive paint. The stimulus current was passed between the filling solution and a wire connected to the paint; hence, this functioned as a concentric bipolar stimulating electrode (Bekkers and Clements, 1999). Layer-specific stimulation of the anterior PC was achieved using well established neuroanatomical landmarks to identify laminae (Neville and Haberly, 2004). LOT stimulation was applied at the border with layer Ia; layer $\mathrm{Ib}$ stimulation was applied at the border with layer IIa. $( \pm)$ Baclofen $(100 \mu \mathrm{M})$ was applied by bath perfusion $(>10 \times$ the bath volume). We noted that baclofen hyperpolarized the resting potential (SL: by $9.7 \pm 0.7 \mathrm{mV}, n=12$; SP: by $4.3 \pm 0.4 \mathrm{mV}, n=12$ ). Hence, in current-clamp experiments (see Figs. 5, 9), following addition of baclofen the resting potential of each cell was returned to its prebaclofen value by steady current injection (typically 10-100 pA).

At the end of the experiment, patch electrodes were carefully withdrawn to preserve the gigaseal, and the slice was fixed for $1 \mathrm{~h}$ in $4 \%$ paraformaldehyde. Only one or (in pair recording experiments) two cells were filled per slice. The tissue was processed with an ABC kit (Vector Laboratories) to recover the morphology of the cells from which recordings were made. Dendritic morphologies were recovered under a $20 \times$ objective using the Neurolucida tracing system (MBF Bioscience).

Data analysis. Electrophysiology analysis (except cluster analysis, below) was done using either Axograph or custom routines written in Igor Pro (WaveMetrics). Passive and active electrical properties were analyzed as previously described (Suzuki and Bekkers, 2006, 2010b). An additional parameter, the subthreshold membrane potential slope, was calculated by fitting a straight line to the voltage response to the largest current step that was subthreshold for eliciting action potentials (APs) (see Fig. $1 B$, gray traces). This fit was done over a 450 -ms-long window starting $50 \mathrm{~ms}$ after the step onset. Synaptic latency (measured for the EPSCs in Fig. 2) was calculated from the peak of the stimulus artifact to the time at which the EPSC reached $10 \%$ of its peak amplitude. AP firing probability (see Figs. 5, 9) was estimated by applying 5 or 10 successive stimuli at each stimulus setting, then counting the fraction of these stimuli that produced an action potential. The charge carried by the delayed ("slow") component of polysynaptic EPSCs (see Fig. 7) was calculated by integrating the EPSC over a 200 -ms-long window starting $20 \mathrm{~ms}$ after the time of the peak of the averaged first (monosynaptic) EPSC. Averaged results are given as mean \pm SEM ( $n=$ number of cells). Statistical comparisons used the paired or unpaired Student's $t$ test with the indicated level of significance.

Cluster analysis. This analysis was done for 61 layer II principal neurons in which 22 electrical parameters and 7 morphological parameters were measured (see Fig. 1). The electrical parameters were as follows: resting potential, input resistance, membrane time constant, sag, latency to first AP, AP rheobase, AP voltage threshold, AP peak, AP height, AP rise time, AP half width, maximum AP upslope and down slope, coefficient of variation of $\mathrm{AP}$ firing variability, $\mathrm{AP}$ accommodation ratio, $\mathrm{AP}$ clustering ratio, peak of the afterhyperpolarization (AHP), AHP height, AHP rise time, AHP half width, subthreshold membrane potential slope, and burst index [calculated as described by Suzuki and Bekkers (2006, 2010b)]. The morphological parameters were as follows: soma crosssectional area, number of dendrites emanating from the soma, number of dendritic branch points, and total dendritic length, where each dendritic parameter was measured separately for the apical and (where present) the basal dendrites. Morphological parameters were calculated using Neurolucida software following neuronal tracing. Note that soma location was not used as an input parameter in the cluster analysis; rather, soma location was used as an independent variable to test the outcome of the analysis (see Fig. $1 D$ ). Each of the above parameters was normalized across all cells to the range $0-1$, and then the data were subjected to an unsupervised tree clustering algorithm based on Euclidean distances with Ward's linkage criterion (Suzuki and Bekkers, 2010b). This analysis was done using the statistics toolbox in Matlab (MathWorks).

\section{Results}

\section{Two broad classes of principal neurons are found in layer II} of the anterior PC

We have previously reported that two functionally distinctive types of glutamatergic principal neurons, SL and SP cells, are present in the main input layer (layer II) of the anterior PC (Suzuki and Bekkers, 2006), confirming neuroanatomical studies 
(Haberly, 1983; Neville and Haberly, 2004). However, our earlier work focused on neurons at the extremities of layer II and did not provide an estimate of the relative numbers of SL and SP cells. Therefore, we reexamined this issue by systematically measuring the electrical and morphological properties of principal neurons across the entire thickness of layer II (Fig. 1).

Whole-cell patch-clamp recordings were made from layer II principal neurons $(n=61)$ selected randomly, but in such a way that their somata were distributed approximately uniformly across the full span of layer II (Fig. 1C). GABAergic neurons, identified by their electrical properties (Suzuki and Bekkers, 2010b), were occasionally encountered and were discarded. The intrinsic electrical properties of each principal neuron were assayed using a series of current steps (see Materials and Methods). After $\sim 15$ min (sufficient time for biocytin in the electrode to equilibrate within the cell), the patch electrode was carefully withdrawn while maintaining the seal. The tissue was then fixed and processed to reveal the morphology of the recorded cell. The dendritic arbors of all 61 neurons in our dataset were traced using reconstruction software (see Materials and Methods).

Typical dendritic morphologies are shown in Figure $1 \mathrm{~A}$. Classic SL cells, lacking basal dendrites, had their somata concentrated in the upper half of layer II (layer IIa) (Fig. 1A, left two cells). Typical SP cells, with profuse apical and basal dendrites, were concentrated in the lower half of layer II (layer IIb) (Fig. $1 A$, right two cells). A third group of neurons, often with their somata located near the center of layer II, had an intermediate dendritic morphology, with apical dendrites and a small number of basal dendrites (Fig. $1 A$, middle two cells).

The intrinsic electrical properties of these neurons are shown in Figure $1 B$ (traces are shown directly below the cell in $A$ from which the recordings were made). These recordings indicated that, notwithstanding the range of morphologies, layer II neurons appeared to fall into just two broad categories: those with SL-like electrical properties [e.g., higher input resistance, longer membrane time constant, smaller spike amplitude (Fig. $1 B$, left three cells)] and those with SP-like properties [e.g., lower input resistance, shorter membrane time constant, larger spike amplitude (Fig. $1 B$, right three cells; Table 1)] (Suzuki and Bekkers, 2006). This distinction was formalized by performing an unsupervised cluster analysis on 22 intrinsic electrical parameters plus 7 morphological parameters for each of the 61 neurons in our dataset (Fig. $1 D$; selected mean parameters in Table 1). The dendrogram confirmed a segregation into two broad groupings: 34 "SL-like" cells, found preferentially in layer IIa (Fig. $1 D$, somatic locations mainly in layer IIa, indicated by predominantly blue

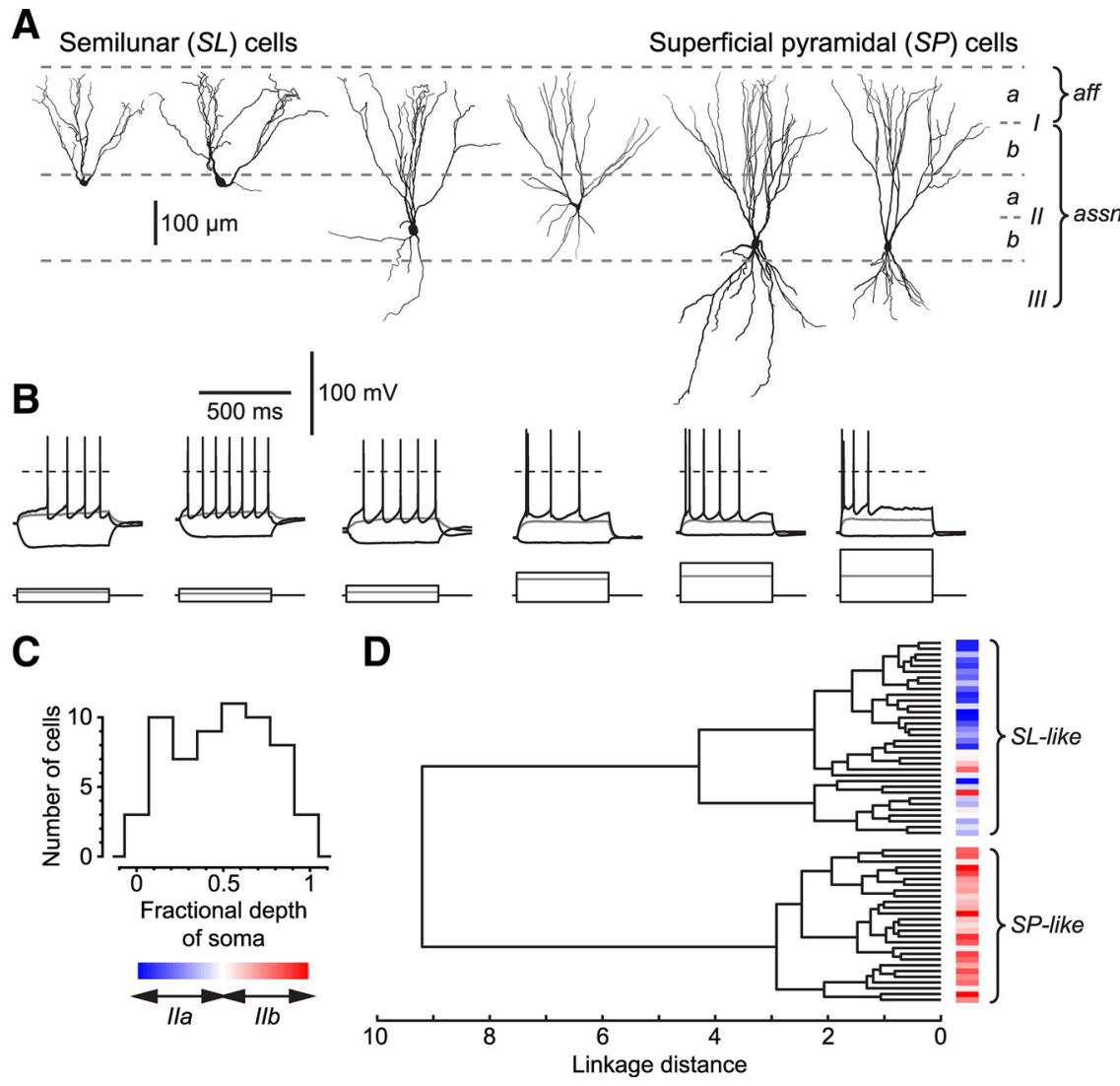

Figure 1. Two broad classes of principal neurons can be identified in layer Il of the anterior PC, based on their morphologies and intrinsic electrical properties. A, Typical dendritic morphologies of layer II principal neurons from which electrical recordings were made. These 作

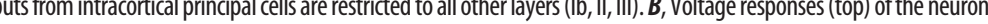
A 500 -ms-long current steps (bottom). The hyperpolarizing step was always $-80 \mathrm{pA}$, and the gray traces show the response to a step (n) in D. Dendrogram showing the result of an unsupervised cluster analysis of the neurons in our dataset, calculated using 7 morphoII) of the soma of each neuron, using the color code in C. Note the separation into two broad classes, as follows: SL-like cells that tend to be found more superficially (mostly blue colors), and SP-like cells that tend to be found deeper (red colors).

colors; see color scale in C), and 27 "SP-like" cells, found only in layer IIb (Fig. $1 D$, somatic locations in layer IIb, indicated by red colors).

These results suggest that there are approximately equal numbers of functionally distinctive SL- and SP-like neurons, concentrated in the superficial and deep subdivisions, respectively, of layer II. However, this separation was not perfect, indicated by some intermixing of "red" and "blue" somatic locations within the SL-like grouping (Fig. 1D). Accordingly, for the remainder of this study we took care to select classic SL and SP neurons located in layers IIa and IIb, respectively, as confirmed from their dendritic morphology and electrical properties (Suzuki and Bekkers, 2006).

Baclofen selectively blocks associational inputs onto both SL and SP cells

Our aim was to compare excitatory synaptic inputs onto SL and SP cells. Both receive two main types of excitatory synaptic input: 
Table 1. Mean and SE of selected parameters used in the cluster analysis

\begin{tabular}{|c|c|c|c|c|c|c|c|}
\hline \multicolumn{4}{|l|}{ Electrical parameters } & \multicolumn{4}{|l|}{ Morphological parameters } \\
\hline & SL-like & SP-like & $p$ & & SL-like & SP-like & $p$ \\
\hline Resting potential (mV) & $-67.2 \pm 0.7$ & $-76.3 \pm 0.7$ & $<0.001$ & Soma cross-sectional area $\left(\mu \mathrm{m}^{2}\right)$ & $268 \pm 7$ & $315 \pm 9$ & $<0.001$ \\
\hline Input resistance $(\mathrm{M} \Omega$ ) & $221.2 \pm 15.2$ & $55.0 \pm 3.5$ & $<0.001$ & $n$ apical dendrites at soma & $2.68 \pm 0.12$ & $1.41 \pm 0.13$ & $<0.001$ \\
\hline Membrane time constant (ms) & $26.0 \pm 1.7$ & $10.1 \pm 0.7$ & $<0.001$ & $n$ basal dendrites at soma & $2.15 \pm 0.32$ & $5.96 \pm 0.38$ & $<0.001$ \\
\hline Sag & $0.91 \pm 0.01$ & $0.93 \pm 0.01$ & 0.22 & Total length of apical dendrites ( $\mu \mathrm{m})$ & $2594 \pm 83$ & $3646 \pm 142$ & $<0.001$ \\
\hline Action potential threshold (mV) & $-36.0 \pm 0.5$ & $-41.5 \pm 0.6$ & $<0.001$ & Total length of basal dendrites ( $\mu \mathrm{m})$ & $448 \pm 84$ & $2022 \pm 159$ & $<0.001$ \\
\hline Action potential halfwidth (ms) & $0.74 \pm 0.01$ & $0.76 \pm 0.01$ & 0.29 & $n$ apical dendritic branch points & $13.0 \pm 0.5$ & $18.5 \pm 0.9$ & $<0.001$ \\
\hline Action potential height (mV) & $76.2 \pm 1.1$ & $92.9 \pm 0.9$ & $<0.001$ & $n$ basal dendritic branch points & $1.5 \pm 0.3$ & $8.6 \pm 0.8$ & $<0.001$ \\
\hline
\end{tabular}

Values were calculated for cells in the SL-like cluster $(n=34)$ and the SP-like cluster $(n=27)$ in Fig. 1D, as described in Materials and Methods. The $p$ values indicate that sag and action potential half widths do not provide a distinction between SL-like and SP-like cells, but all the other parameters listed here do support a clear distinction, on average.

A Stim LOT

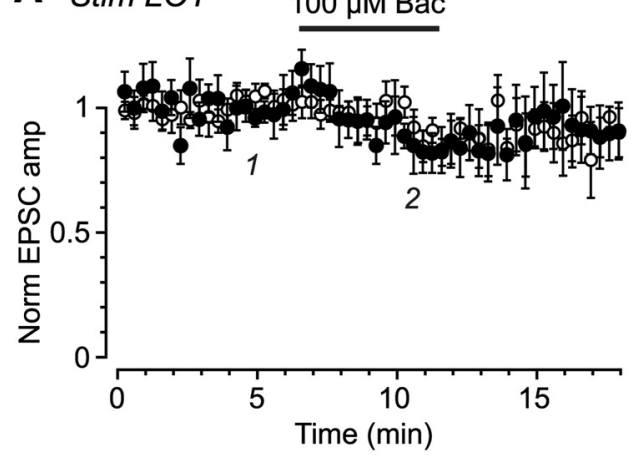

B Stim Ib

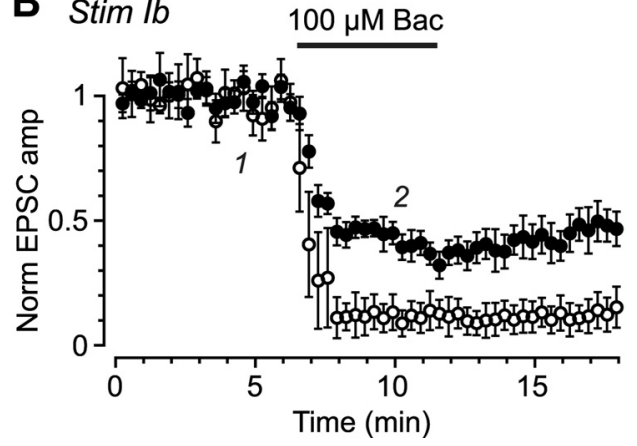

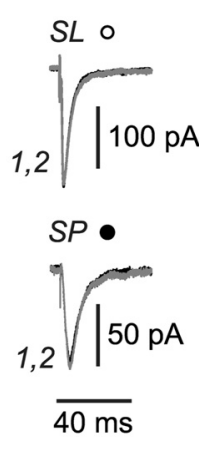
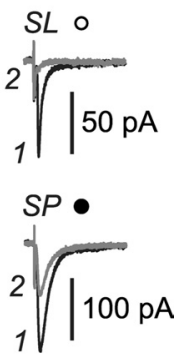

$\overline{40 \mathrm{~ms}}$

Figure 2. Excitatory synaptic inputs onto both SL and SP cells in the PC can be selectively inhibited with baclofen. $A$, Plot of mean peak amplitude of EPSCS, normalized to the mean amplitude during the first 5 min of recording, versus time for SL cells (open symbols, $n=5$ cells) and SP cells (filled symbols, $n=5$ ) while stimulating the LOT afferent input from the olfactory bulb. Error bars show \pm SEM. (士)-Baclofen (100 $\mu \mathrm{m}$, bath-applied during period shown by the horizontal bar) had little effect on EPSC amplitude in both SL and SP cells. Insets at right show typical EPSCs recorded at the indicated time points (1, baseline, black traces; 2 , at end of baclofen application, gray traces). $\boldsymbol{B}$, Same as $\boldsymbol{A}$, except for EPSCs recorded while stimulating the assn input in layer $\mathrm{lb}$ ( $n=5$ for SL cells; $n=6$ for SP cells). The Ib input to both SL and SP cells was strongly inhibited by $100 \mu \mathrm{m}$ baclofen.

afferent (aff) fibers emanating via the LOT from mitral/tufted cells in the olfactory bulb, and associational (assn) inputs that mainly arise from other principal cells in the ipsilateral and contralateral PC (Neville and Haberly, 2004; Suzuki and Bekkers, 2006). Aff and assn inputs are strictly segregated into layer Ia and layers Ib-III, respectively, facilitating their selective excitation (Fig. 1A). However, stimulation of aff inputs can often lead to polysynaptic excitation of assn fibers, complicating the interpretation. One way to overcome this problem is to bath-apply the $\mathrm{GABA}_{\mathrm{B}}$ agonist, baclofen, which has been reported to selectively block assn inputs onto layer II SP cells (Tang and Hasselmo, 1994), thereby allowing pharmacological isolation of aff inputs onto pyramidal cells (Franks and Isaacson, 2005, 2006; Poo and Isaacson, 2007). Hence, we began by checking whether baclofen is also useful for isolating aff inputs onto SL cells.

Weak stimulation at the LOT/layer Ia border produced monosynaptic, presumed aff EPSCs in both SL and SP cells (mean synaptic latency from stimulus artifact to EPSC onset: SL, $1.11 \pm 0.06 \mathrm{~ms}, n=4$; SP, $1.47 \pm 0.21 \mathrm{~ms}, n=4)$. Bath perfusion of $( \pm)$-baclofen $(100 \mu \mathrm{M})$ had little effect on LOT-evoked (aff) EPSCs in both SL and SP cells (Fig. 2A) (SL: inhibition $0.88 \pm$ 0.03 , measured 5 min after start of baclofen perfusion, $n=5$ cells; SP: inhibition $0.83 \pm 0.04, n=5$; no difference between SL and SP cells, $p>0.1$ ). Upon moving the stimulating electrode to the layer Ib/IIa border, weak stimulation produced monosynaptic, presumed assn EPSCs in both cell types (mean synaptic latency: $\mathrm{SL}, 1.76 \pm 0.18 \mathrm{~ms}, n=4$; SP, $1.54 \pm 0.10 \mathrm{~ms}, n=6$ ). In contrast to aff EPSCs, baclofen strongly inhibited assn-evoked EPSCs in both cell types, with significantly greater inhibition observed in SL cells (Fig. $2 B$ ) (SL: inhibition $0.12 \pm 0.01, n=5$ cells; SP: inhibition $0.37 \pm 0.02, n=6$; significantly different, $p<0.05)$. Thus, these data confirm previous findings for SP cells (Tang and Hasselmo, 1994; Franks and Isaacson, 2005) and extend the results to SL cells. In experiments described below we will make use of these findings by using baclofen to suppress assn inputs to both SL and SP cells.

\section{SL cells receive stronger aff input and SP cells receive stronger assn input}

Next, we wished to perform a simple experiment comparing the strength of the two kinds of excitatory synaptic input (aff and assn) onto the two classes of layer II principal cells (SL and SP). Simultaneous whole-cell voltage-clamp recordings from an SL cell and a nearby $(<150 \mu \mathrm{m})$ SP cell were obtained (Fig. $3 A$ ), and then an extracellular stimulator was placed either at the LOT/Ia border (to excite aff inputs) or at the layer Ib/IIa border (to excite assn inputs). Baclofen $(100 \mu \mathrm{M})$ was present in the bath when stimulating the LOT to minimize contamination from polysynaptic assn excitation, although broadly similar results were also obtained in the absence of baclofen.

Over a wide range of stimulation intensities, LOT stimulation produced larger EPSCs in SL cells than in SP cells (Fig. 3B, left; responses to two stimulation intensities shown superimposed). The opposite result was found for layer Ib stimulation, which elicited much larger EPSCs in SP cells (Fig. 3B, right). These results were summarized by plotting the EPSC amplitude measured in an SL cell versus that measured simultaneously in an SP cell for a range of stimulus strengths, averaging across $n=6$ cell pairs (Fig. 3C). With LOT stimulation, the points lay above the diagonal (averaged slope $2.41 \pm 0.34$ ), indicating that SL cells receive stronger aff inputs. Conversely, with layer Ib stimulation, the points lay below the diagonal (averaged slope $0.063 \pm 0.017$ ), showing that SP cells receive stronger assn inputs. 

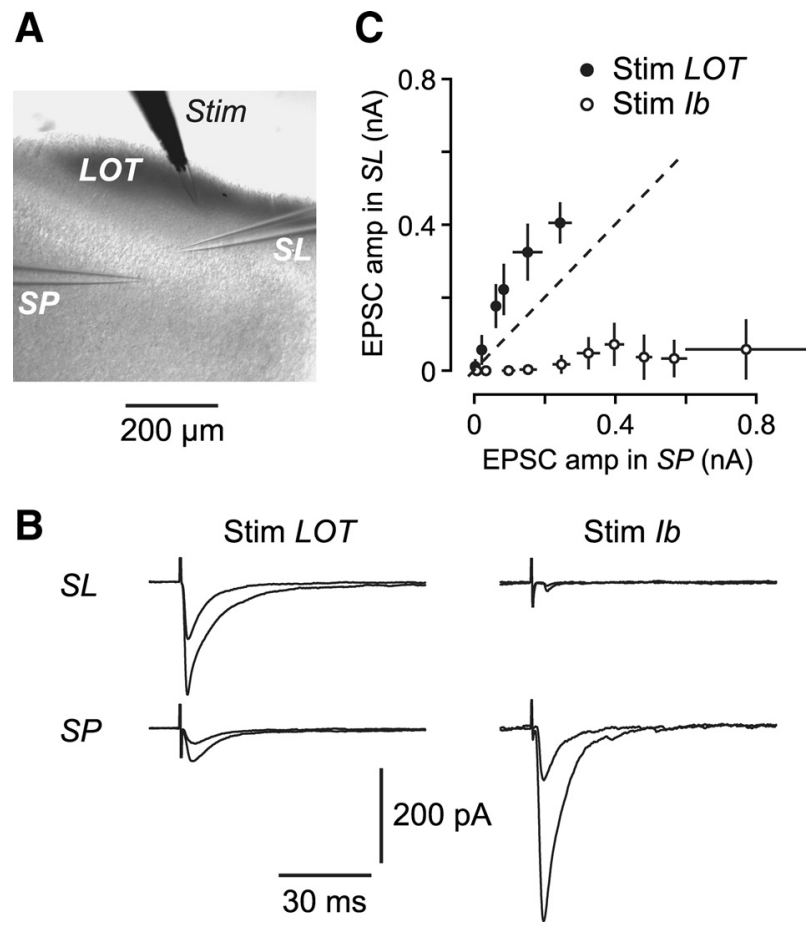

Figure 3. Dual recordings from an SL and an SP cell show that SL cells receive stronger LOT (aff) inputs, whereas $\mathrm{SP}$ cells receive stronger $\mathrm{Ib}$ (assn) inputs. $A$, Image showing the arrangement of electrodes. Simultaneous whole-cell recordings were obtained from an identified SL cell (layer Ila) and SP cell (layer Ilb), and an extracellular stimulating (Stim) electrode was placed in either the LOT (illustrated) or in layer Ib. B, Typical EPSCs recorded in this experiment. Each panel shows two EPSCs elicited by two different stimulus strengths in an SL cell (top) and an SP cell (bottom) while stimulating in the LOT (left) or in layer lb (right). The stimulus artifact has been clipped. When recording the LOT response, the bath solution contained $100 \mu \mathrm{m}$ baclofen to block contamination by assn inputs. Baclofen was omitted when recording the response to layer Ib stimulation. C, Summary plot showing the mean EPSC amplitude measured in SL cells versus the mean amplitude in SP cells when stimulating either the LOT (filled symbols above the diagonal dashed line) or layer Ib (open symbols below the diagonal). Each point is the decimated average of 10 individual measurements made at a similar stimulus strength $(n=6$ cells). Error bars indicate \pm SEM.

\section{Minimal stimulation reveals the basis for different synaptic strengths in SL and SP cells}

What is the physiological basis for these different input strengths? We addressed this question by using minimal extracellular stimulation to isolate single aff or assn fibers contacting SL and SP cells (Fig. 4). Small increments in a weak stimulation current often elicited a step-like increase in the EPSC (Fig. 4A); this is interpreted as being due to the all-or-none excitation of a single axon, producing a unitary synaptic response (Bekkers and Clements, 1999; Franks and Isaacson, 2006). The amplitude of this unitary response, estimated from the mean amplitude of the plateau in the stimulus-response plot (Fig. $4 \mathrm{~A}$ ), was measured for a number of different cells and accumulated into a frequency histogram for each kind of input onto each cell type (Fig. 4B).

The distribution of amplitudes of unitary aff inputs onto SL cells was $\sim 3.6 \times$ larger on average and more skewed to the right than was the distribution for unitary aff inputs onto SP cells (Fig. $4 B$, left) (SL: mean amplitude of unitary EPSCs, $70.7 \pm 9.5 \mathrm{pA}$, $n=29$; SP: mean amplitude, $19.4 \pm 2.3 \mathrm{pA}, n=20 ; p<0.001$ ). This suggests that the larger aff response in SL cells described earlier (Fig. 3) is due to a more powerful unitary synaptic connection from aff axons onto SL cells. Note that we never observed larger unitary EPSC amplitudes in SP cells with stronger LOT stimulation, as has been reported for unidentified principal cells
A

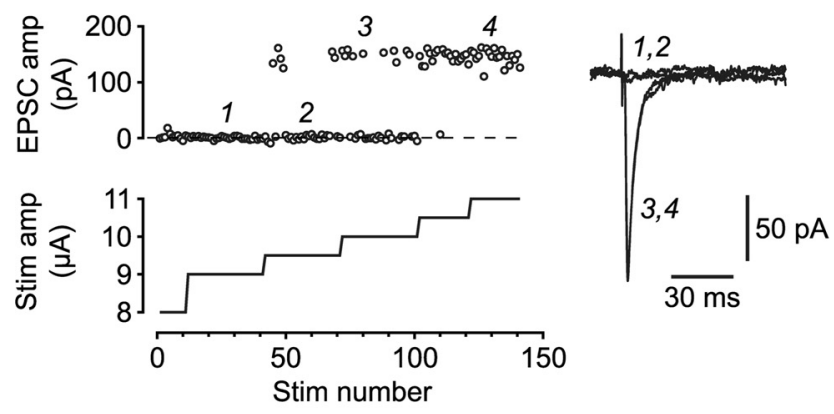

B

Stim LOT

Stim $I b$
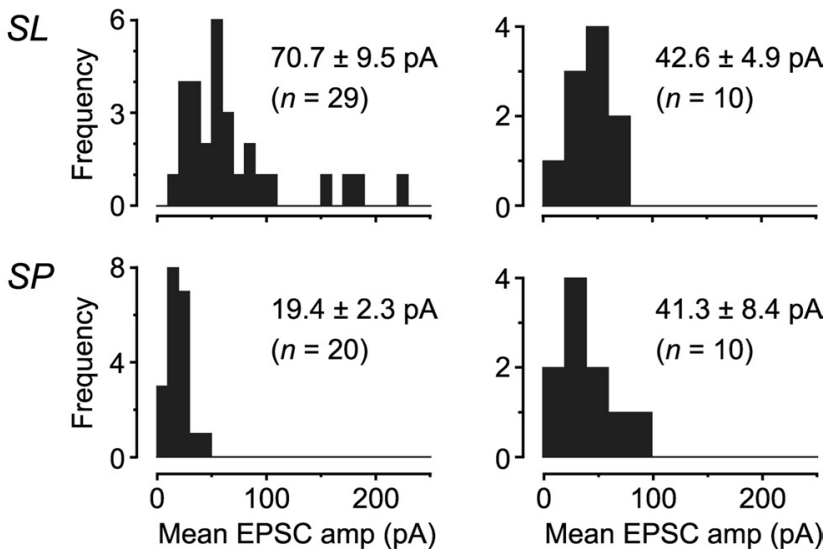

Figure 4. Minimal extracellular stimulation shows that unitary LOT inputs onto SL cells tend to be larger than those onto SP cells, whereas unitary layer Ib inputs onto both cell types are similar. $\boldsymbol{A}$, Data from a typical cell (SL) showing how unitary responses were measured. The amplitude of the stimulator current (Stim; bottom) was increased in small steps close to the threshold for eliciting an EPSC (top). The mean EPSC amplitude during the plateau response was taken to be the unitary EPSC amplitude (here, $152 \mathrm{pA}$ ). Inset at right shows traces recorded at the indicated points on the time course plot. Baclofen was not used in these experiments because stimulation strengths were too weak to elicit contaminating assn inputs. $\boldsymbol{B}$, Histograms showing the distributions of unitary EPSC amplitudes measured in experiments like in $A$, for SL cells (top row) or SP cells (bottom row) while stimulating either the LOT (left column) or layer Ib (right column). Numbers to the right of each histogram represent the mean of the unitary amplitudes ( \pm SEM) included in the histogram ( $n=$ number of cells).

in layer II/III of rat PC (Franks and Isaacson, 2006). Thus, SP cells in mouse PC appear to receive only relatively weak single-fiber inputs.

In contrast to aff inputs, the distribution of unitary amplitudes for assn inputs was not significantly different in SL and SP cells (Fig. $4 B$, right) (SL: mean amplitude of unitary EPSCs, $42.6 \pm 4.9 \mathrm{pA}, n=10$; SP: mean amplitude, $41.3 \pm 8.4 \mathrm{pA}, n=$ $10 ; p=0.89)$. How can this be reconciled with the earlier finding (Fig. 3) that multifiber stimulation of assn inputs gives a larger response in SP cells? A possible explanation is that SP cells are more densely innervated by assn fibers than SL cells are; that is, stronger extracellular stimulation may simply recruit more SP cell-targeting assn axons. This is consistent with the observation that SP cells have many more dendrites and dendritic spines in the assn layers than SL cells have (Haberly, 1983); that is, SP cells provide a larger target for assn axons and so receive more inputs (see Discussion).

Input- and cell type-specific stimulus thresholds for synaptically evoked action potentials

Having used voltage-clamp recordings to measure differential synaptic input strengths to SL and SP cells, we next turned to 


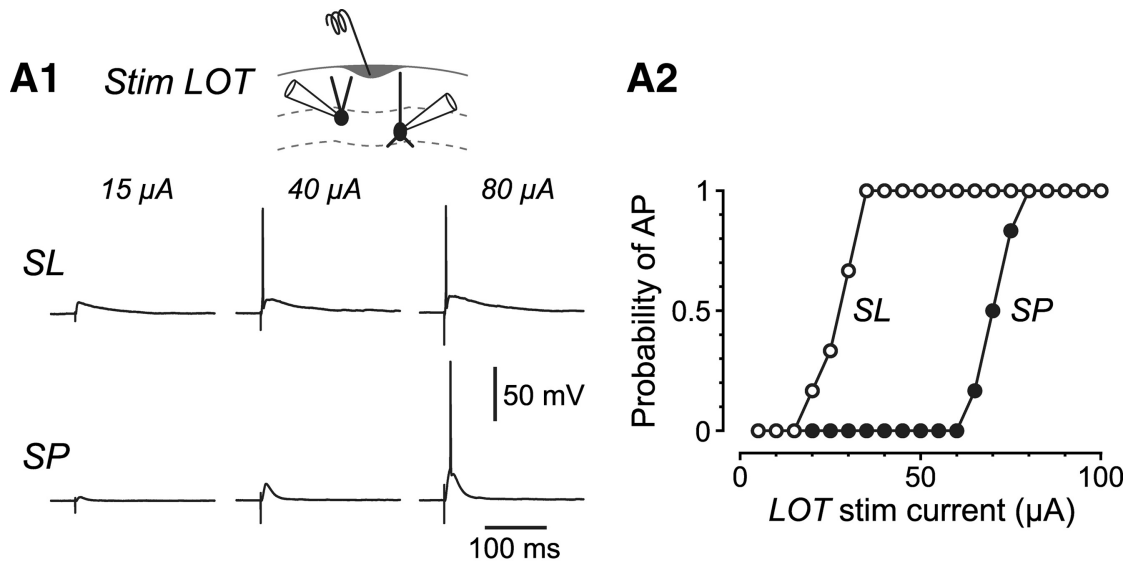

B1 Stim Ib

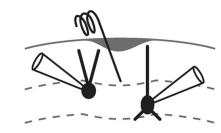

$5 \mu A$

\begin{abstract}
$40 \mu A$
\end{abstract}
$80 \mu A$
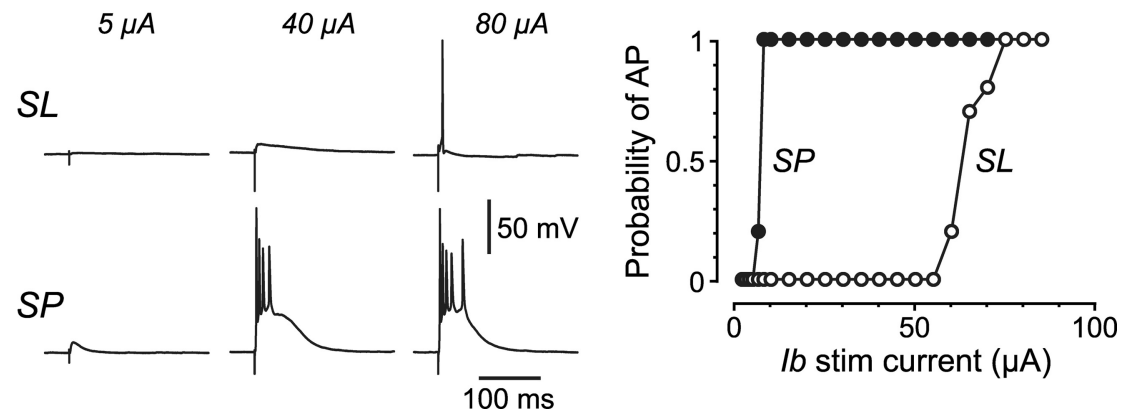

Figure 5. The differential strength of LOT and layer Ib synaptic inputs onto SL and SP cells (as shown in Fig. 3, using voltage clamp) is also manifested as differential AP firing thresholds (measured using current clamp). $A_{\boldsymbol{1}}$, Simultaneous whole-cell currentclamp recordings from an SL cell (top row) and an SP cell (bottom row) while stimulating (Stim) the LOT with the indicated currents $(15,40,80 \mu \mathrm{A})$. Inset at top shows schematically the recording configuration. $\boldsymbol{A}_{2}$, Analysis of data from the cells in $\boldsymbol{A}_{\boldsymbol{1}}$, plotting the probability of firing at least one AP versus the current strength applied to the stimulator in the LOT. The SL cell (open symbols) reaches AP threshold at much lower stimulation currents than the SP cell (filled symbols). Similar results were obtained in six cell pairs. The bath solution contained $100 \mu \mathrm{m}$ baclofen to block contamination by assn inputs. $\boldsymbol{B}_{\boldsymbol{1}}, \boldsymbol{B}_{2}$, Similar experiment while stimulating in layer Ib. Now, the pattern of excitability is reversed: with assn inputs, the SP cell reaches AP threshold at much lower stimulation currents than the SL cell. Similar results were obtained in five cell pairs. Baclofen was not present during these measurements.

current-clamp recordings to determine the consequences of these findings for postsynaptic excitability. Simultaneous whole-cell current-clamp recordings were made from an SL cell and a nearby SP cell while stimulating either aff inputs [with 100 $\mu \mathrm{M}$ baclofen in the bath (Fig. 5A)] or assn inputs [without baclofen (Fig. 5B)]. In each case, a stimulus-response plot was constructed in which the probability of firing at least one synaptically evoked action potential was plotted versus the amplitude of the stimulation current (Fig. $5 A_{2}, B_{2}$ ).

When stimulating aff inputs in the LOT, a much weaker stimulus was able to elicit synaptically evoked APs in SL cells compared with SP cells (Fig. 5A) (stimulus current required to generate at least one AP with a probability of 0.5 was 2.6-fold lower in the SL cell in Fig. 5A compared with the SP cell; average from $n=6$ experiments of this type $=3.7 \pm 0.7$-fold lower stimulation required in SL cells). SL cells also had a larger input resistance than SP cells $(236 \pm 9 \mathrm{M} \Omega$ compared with $48 \pm 4 \mathrm{M} \Omega$, $n=6$ each, $p<0.001)$ and a more depolarized resting potential $(-66.6 \pm 2.0 \mathrm{mV}$ compared with $-80.6 \pm 0.5 \mathrm{mV}, n=6$ each, $p<0.001$ ), in agreement with our earlier report (Suzuki and Bekkers, 2006). That is, SL cells not only receive a stronger aff input, but are also more readily depolarized by that input.
The opposite result was obtained when stimulating assn inputs in deep layer Ib (Fig. 5B): synaptically evoked APs occurred with much weaker stimulus strengths in SP cells (8.9-fold lower stimulus current required to elicit APs in the SP cell in Fig. $4 B$ compared with the SL cell; average $=7.0 \pm 1.8$-fold lower stimulation required in SP cells, $n=6)$. This behavior reflects the much larger assn synaptic input received by SP cells (Fig. 3).

In summary, these results show that synaptically driven APs mimic the behaviors described earlier for EPSCs: SL cells fire more readily in response to singleshock aff inputs, whereas SP cells fire more readily in response to single-shock assn inputs.

\section{Tissue cut experiments are consistent with stronger aff input to SL cells} We next explored another consequence of the stronger aff input to SL cells by using a mechanical method to isolate assn inputs. A cut was made across the LOT and layer Ia, then the stimulating electrode was placed at the LOT/Ia border on one side of the cut, and a recording was made from an $\mathrm{SP}$ cell on the other side of the cut (Fig. $6 A)$. With this arrangement, direct aff input from the stimulator to the SP cell is prevented; instead, only polysynaptic feedforward excitation via deeper assn fibers should be visible in the SP cell. This feedforward excitation could be provided by either an SP or an SL cell (Fig. 6A, two cells at left). It is also possible that other principal neurons may interpose between the directly stimulated (SL or SP) cell and the recorded (SP) cell, prolonging the delay between the stimulus and response. However, here we are only interested in the circuit which gives the shortest possible delay. This will allow us to determine whether SL or SP cells are preferentially stimulated by LOT input.

First, we measured the latency between stimulation of the LOT and the appearance of a monosynaptically evoked action potential in an SL or SP cell; i.e., the first stage of the circuit in Figure $6 \mathrm{~A}$. The stimulus strength was adjusted to be just above threshold for eliciting an AP in the recorded cell (5-30 $\mu$ A for SL; $30-70 \mu \mathrm{A}$ for SP) (Fig. $6 B_{1}$ ). The mean latency from the stimulus to the AP peak was significantly shorter in SL cells than in SP cells (SL: $3.9 \pm 0.1 \mathrm{~ms}, n=4$; SP: $8.7 \pm 0.1 \mathrm{~ms}, n=4$; $p<0.001$ ) (Fig. $\left.6 B_{2}\right)$. Both latencies became smaller as the LOT stimulus strength was increased, but the latency in SL cells was consistently 2-4 ms briefer than that in SP cells (Suzuki and Bekkers, 2006).

Next, we weakly stimulated the LOT while recording from an SP cell on the other side of the tissue cut (as in Fig. 6A). Initially, $\mathrm{GABA}_{\mathrm{A}}$ receptor antagonists were not present for these experiments. A typical response is shown in Figure 6C, top. Most commonly, the EPSC in the SP cell had a mean latency of 3.9-5.5 ms ( $n=14$ cells; e.g., for the cell in Fig. $6 C$, mean latency is $4.40 \pm$ $0.02 \mathrm{~ms}, n=230$ trials). This EPSC was inhibited by $100 \mu \mathrm{M}$ 


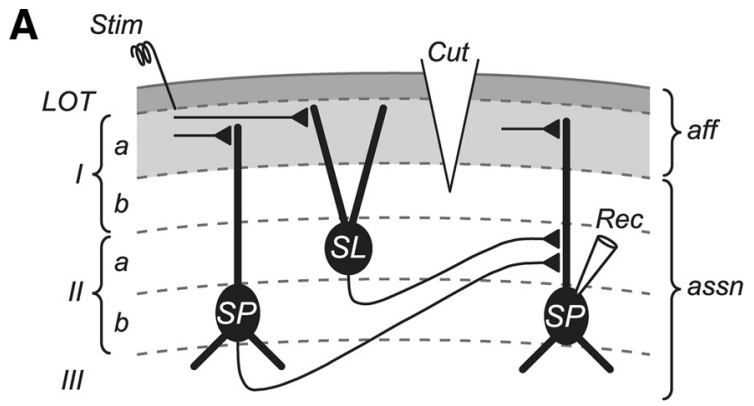

B1

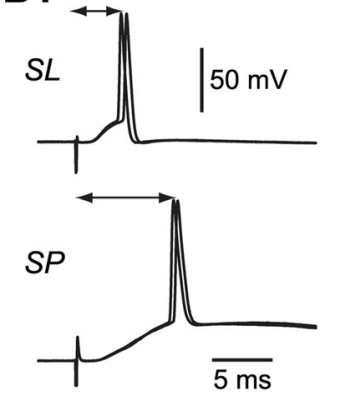

B2
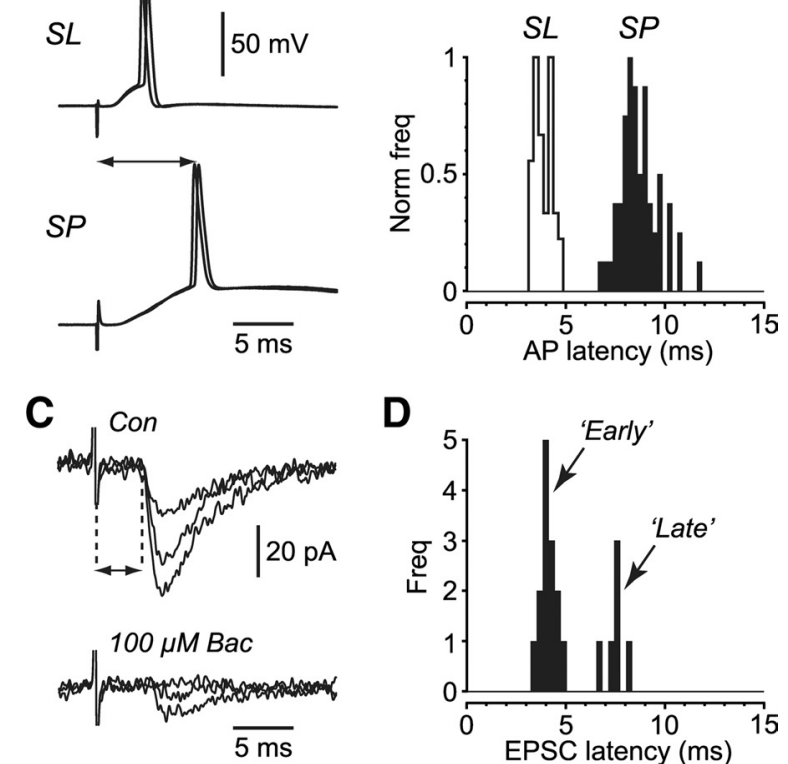

D

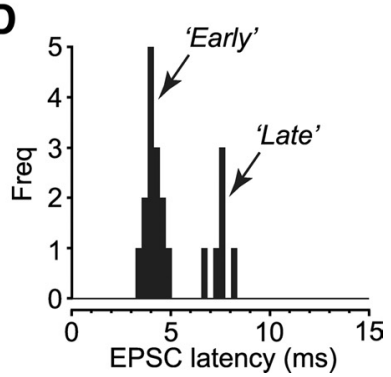

Figure 6. When direct aff input to SP cells is prevented by a tissue cut, weak stimulation of the LOT reveals a feedforward excitatory assn input that is largely driven by SL cells. $A$, Schematic diagram showing the recording configuration, illustrated for a parasagittal slice containing the LOT. The LOT and layer la (gray) are transected by a tissue cut. The extracellular stimulating electrode (Stim) is placed at the LOT/la border on one side of the cut, while recordings are made from an SP cell on the other side of the cut. Weak stimulation excites aff input to either an SP cell or an SL cell, which in turn provides assn input to the recorded SP cell. $\boldsymbol{B}_{\boldsymbol{1}}$, Two superimposed episodes recorded in an SL cell (top) and an SP cell (bottom) showing synaptically evoked APs at stimulus strengths just above threshold for eliciting APs. The bath solution did not contain picrotoxin. $\boldsymbol{B}_{\mathbf{2}}$, Histograms of the latency from the stimulus to the peak of the synaptically evoked AP (arrowed in $\boldsymbol{B}_{1}$ ), combining measurements on $n=4 \mathrm{SL}$ cells and $n=4 \mathrm{SP}$ cells. C, Top, Superimposed episodes recorded from an SP cell following weak LOT stimulation with the electrode configuration as in $\boldsymbol{A}$, showing EPSCs that result from the feedforward excitation of assn inputs. The synaptic latency is arrowed. The mean synaptic latency in this cell was $4.40 \pm 0.02 \mathrm{~ms}$ ( $n=230$ trials). C, Bottom, Episodes from the same cell after application of 100 $\mu \mathrm{m}$ baclofen. Inhibition of the EPSCs confirms the involvement of assn fibers. $\boldsymbol{D}$, Histogram of mean synaptic latencies for 20 experiments as in $\boldsymbol{C}$. Two classes of cells are apparent, with "Early" (mean $4.6 \pm 0.1 \mathrm{~ms}, n=14)$ and "Late" $(8.0 \pm 0.2 \mathrm{~ms}, n=6)$ EPSC latencies.

baclofen (Fig. 6C, bottom), confirming that it involved an assn input (same result in $n=20$ cells). Addition of bicuculline (10 $\mu \mathrm{M})$ to block synaptic inhibition had no effect, but the EPSC was completely blocked by addition of DNQX $(10 \mu \mathrm{M})$ and D-APV ( $50 \mu \mathrm{M}$; data not shown; $n=20$ cells). Less commonly, weak LOT stimulation produced an EPSC with a longer mean latency (7.1$8.7 \mathrm{~ms}, n=6$; data not shown). A histogram of mean EPSC latencies in 20 experiments of this kind showed two populations: a majority $(14 / 20=70 \%)$ with a mean latency of $4.6 \pm 0.1 \mathrm{~ms}$ ("Early"), the remainder (30\%) with a mean latency of $8.0 \pm 0.2$ ms ("Late") (Fig. 6D).
Critically, these data show that the majority population of early EPSCs (those appearing at $4.6 \pm 0.1 \mathrm{~ms}$ after the stimulus) could only have been driven by action potentials in SL cells (which occur at $3.9 \pm 0.1 \mathrm{~ms}$ after the stimulus) (Fig. 6 B2). In contrast, SP cells only fire after these early EPSCs appear. Moreover, the difference between these two latencies $(4.6-3.9=0.7$ $\mathrm{ms}$ ) is compatible with a propagation delay in the SL cell axon plus a delay at the SL $\rightarrow$ SP cell synapse. These results strongly suggest that, following LOT stimulation, SL cells provide the main excitatory feedforward input that drives assn pathways, again consistent with the idea that SL cells receive the strongest aff input. However, we cannot exclude the possibility that a minority of EPSCs (the 30\% with a longer latency) are driven by SP cells, or perhaps by a chain of SL and SP cells.

\section{Epileptiform activity is associated with stronger assn input to SP cells}

With the exception of Figures 3 and 5, the experiments described so far used relatively weak stimulation currents $(<70 \mu \mathrm{A})$ to minimize epileptiform discharges in these disinhibited slices. [Picrotoxin $(100 \mu \mathrm{M})$ was present in most experiments to prevent contamination of excitatory postsynaptic responses by $\mathrm{GABA}_{\mathrm{A}}$ receptor-mediated inhibitory responses.] For the next series of experiments we used stronger stimulation currents (up to 150 $\mu \mathrm{A})$ to elicit epileptiform polysynaptic activity.

Simultaneous whole-cell voltage-clamp recordings were made from an SL-SP cell pair (Fig. 7 $A_{1}$ ) or from two SP cells (Fig. $7 A_{2}$ ) while stimulating the LOT. The initial EPSC, largely due to monosynaptic aff input (see below), was often followed by an asynchronous burst of EPSCs with a much longer latency (Fig. $7 A$, arrowed). The latency of this burst was highly variable between stimuli, but was synchronized in both cells (quantification not shown). When recording from SL-SP cell pairs, the asynchronous burst appeared to be consistently smaller in the SL cell (Fig. $7 A_{1}$; compare arrowed events), whereas the bursts were of similar size in SP-SP cell pairs (Fig. $7 A_{2}$, arrowed). This observation was quantified by integrating the charge carried by the delayed phase of each current trace (see Materials and Methods), and then plotting the charge measured in one cell against that measured in the other (Fig. $7 B_{1}$ ). Sweep-to-sweep fluctuations in the amplitudes of this charge gave rise to a cloud of points distributed along a straight line (correlation coefficients: SL + SP: 0.56 ; SP + SP, 0.93). The different slopes of these lines confirm that the asynchronous response is much smaller in the SL cell (Fig. $7 B_{1}$ ) (SL + SP pair: slope of line, 0.10 ; SP + SP pair: slope, 1.71). Averaged data from a number of cells confirmed this finding (Fig. $7 B_{2}$ ) (averaged mean slow charge: SL, $4.2 \pm$ $1.0 \mathrm{pC}, n=4$ cells; SP, $26.5 \pm 4.3 \mathrm{pC}, n=12$ cells; significantly different, $p=0.012$ ).

We hypothesized that the delayed asynchronous EPSCs observed in this experiment were generated by recurrent activity via assn fibers. If so, addition of baclofen $(100 \mu \mathrm{M})$, which selectively blocks assn inputs to both SL cells and SP cells (Fig. 2), should abolish the asynchronous responses. This was found to be the case (Fig. 7C) (SL cells: mean slow charge $4.2 \pm 1.0 \mathrm{pC}$ in control, $0.42 \pm 0.11 \mathrm{pC}$ in baclofen, $n=4, p<0.05$; SP cells: mean slow charge $25.8 \pm 6.5 \mathrm{pC}$ in control, $0.84 \pm 0.31 \mathrm{pC}$ in baclofen, $n=$ $8, p<0.01)$.

For the SP cell shown in Figure 7C, baclofen also inhibited the early EPSC (Fig. 7C, bottom; compare amplitudes of EPSCs immediately following the stimulus). However, examination on a faster timescale shows that this early EPSC contains two components: an initial baclofen-resistant component, presumably due 

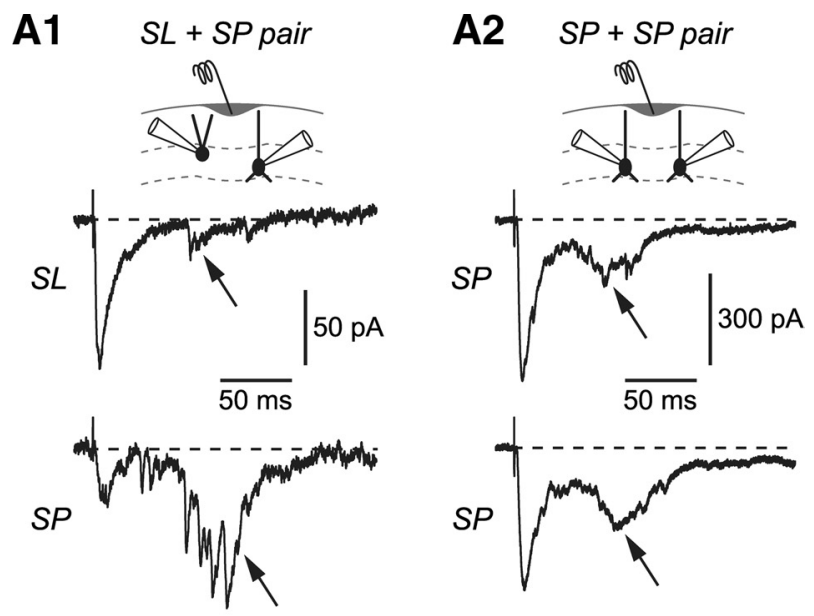

B1

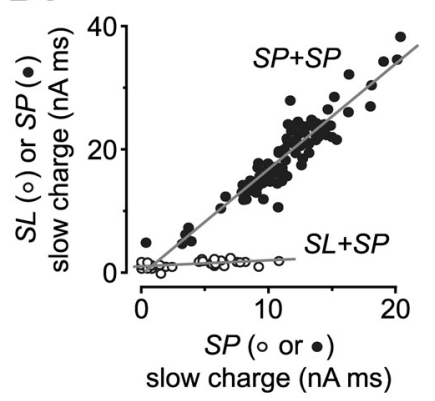

B2

0

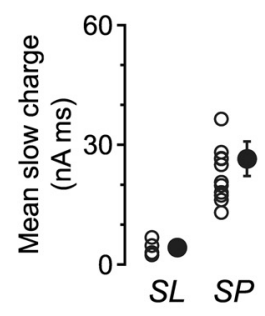

C

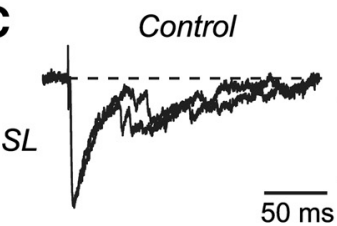
$50 \mathrm{pA}$
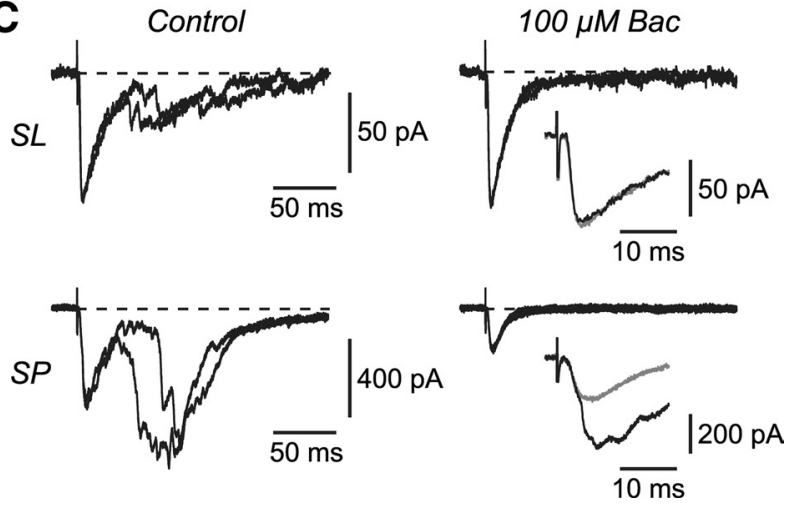

Figure 7. When larger stimulus currents are applied to the LOT in disinhibited slices, strong polysynaptic assn excitation is apparent in SP cells but not in SL cells. This excitation is blocked by baclofen. $A_{1}$, Simultaneous whole-cell recordings from an SL cell (top) and an SP cell (bottom) while stimulating the LOT in the presence of $100 \mu \mathrm{m}$ picrotoxin. Long-latency polysynaptic EPSCS (arrowed) are much larger in the SP cell than in the SL cell. Similar observations were made in $n=4$ pairs. $\boldsymbol{A}_{2}$, A similar experiment involving two SP cells. The polysynaptic EPSCS (arrows) are large in both cells. They also exhibit synchronous latency jitter (not illustrated). $\boldsymbol{B}_{\boldsymbol{1}}$, Analysis of the data from the cell pairs in $\boldsymbol{A}_{\boldsymbol{1}}, \boldsymbol{A}_{2}$. Slow charge (a measure of the size of the long-latency polysynaptic EPSC) was calculated by integrating over a 200-ms-long window starting $20 \mathrm{~ms}$ after the peak of the averaged first EPSC (see Materials and Methods). The slow charge measured in one cell was plotted against that measured in the other. Sweep-to-sweep fluctuations in the amplitudes of this charge gave rise to a cloud of points distributed along a straight line (correlation coefficients: SL + SP:0.56; SP + SP, 0.93). The slope was larger for the SP + SP pair, reflecting the larger polysynaptic EPSCs in SP cells (SL + SP:0.10; SP + SP:1.71). $\boldsymbol{B}_{2}$, Summary plot showing the mean slow charge measured in individual cells (open symbols; $S L, n=4 ; S P, n=12$ ) and the grand mean for each cell type (filled symbols with error bars, \pm SEM). These values were significantly different $(p=0.012)$. C, Simultaneous whole-cell recordings from an SL cell (top) and an SP cell (bottom) before (left) and after (right) perfusing $100 \mu \mathrm{m}$ baclofen in the bath solution. Each panel shows two superimposed sweeps recorded in each cell. Baclofen blocks the long-latency polysynaptic EPSCs in both cell types and also blocks a putative polysynaptic component in the initial EPSC recorded in the SP cell. The insets (right) show the initial EPSC expanded (black: before baclofen; gray: after baclofen). to monosynaptic aff input, and a slightly delayed component, presumably mediated by disynaptic assn excitation, which is selectively blocked by baclofen (Fig. $7 C$, inset at lower right). In contrast, the early EPSC in the SL cell (Fig. 7C, top) was unaffected by baclofen and must be entirely due to monosynaptic aff input. Similar results were obtained in $n=4$ cell pairs.

In summary, stronger stimulation of the LOT in disinhibited slices evokes a much larger delayed, polysynaptic response in SP cells than in SL cells, and this polysynaptic response is mediated by baclofen-sensitive assn inputs. This result is consistent with the finding (Figs. 3, 5) that SP cells receive a larger assn input than SL cells receive.

\section{SL and SP cells respond differentially to trains of synaptic stimuli}

So far we have focused on the responses of SL and SP cells to single-shock stimuli. In vivo these cells are thought to receive brief bursts of excitation at $\sim 10-40 \mathrm{~Hz}$ (Cang and Isaacson, 2003; Suzuki and Bekkers, 2006). Therefore, we next examined the responses of these two cell types to trains of 10 pulses of synaptic stimulation at frequencies in the range of 5-100 Hz.

Whole-cell voltage-clamp recordings were made from either SL cells or SP cells (Fig. 8, top and bottom, respectively) while stimulating either the LOT or layer Ib (Fig. 8, left and right, respectively). EPSC amplitudes during each train were normalized to the first in the train. Aff (LOT-evoked) responses in SP cells showed the most complex changes in EPSC amplitude during trains, with initial facilitation at all frequencies tested, followed by depression at the higher $(20-100 \mathrm{~Hz})$ stimulation frequencies (Fig. $8 C$ ). The facilitation is consistent with previous reports of paired-pulse facilitation at these inputs (Bower and Haberly, 1986; Hasselmo and Bower, 1990; Suzuki and Bekkers, 2006). In contrast, assn (layer Ib-evoked) inputs onto SP cells and aff and assn inputs onto SL cells all showed similar behavior, with little facilitation at any frequency and pronounced depression at the higher stimulation frequencies (Fig. $8 A, B, D$ ).

\section{Short-term synaptic facilitation in SP cells partially compensates for their weaker aff input}

The results in the previous section emphasize that aff inputs onto SP cells are unusual in that they exhibit striking short-term synaptic dynamics. This behavior is likely to have ramifications for our earlier conclusions about the responsiveness of SP cells to LOT stimulation (Figs. 3, 5). Accordingly, we revisited our earlier experiments studying the strength of aff inputs onto SP cells (Fig. 5), this time using trains of stimuli rather than single shocks.

Simultaneous whole-cell current-clamp recordings were made from an SL cell and a nearby SP cell, as before (Fig. 5). A 50 $\mathrm{Hz}$ train of three stimuli at a range of stimulus strengths (5-100 $\mu \mathrm{A})$ was applied at the LOT/layer Ia border. Baclofen $(100 \mu \mathrm{M})$ was present to inhibit assn inputs. During the train, the amplitude of the EPSP in SP cells increased due to short-term facilitation (Fig. 9A, bottom gray inset), whereas the amplitude in SL cells did not (Fig. 9A, top gray inset). As a result, SP cells tended to fire APs more readily later in the train. The data were analyzed by plotting the probability of firing at least one AP on any EPSP in the train versus stimulus current (Fig. 9B, black symbols and lines). Also plotted on the same axes is the probability of firing at least one AP on the first EPSP in the train (Fig. 9B, red symbols and lines), to allow easy comparison with the experiment in Figure 5 in which only a single EPSP was elicited.

By allowing APs to occur anywhere in a train of three EPSPs, the difference between the two cell types was now reduced (Fig. 
$9 B$, red arrow) as follows: SP cells now required only $1.9 \pm 0.3$-fold larger stimulus current ( $n=10$ pairs) than did SL cells to elicit at least one AP in a train (compared with a $3.7 \pm 0.5$-fold stronger stimulation for a single stimulus; $p<0.02$; compare Fig. 5A). Thus, the relative sensitivity of SL and SP cells to aff input depends on the dynamics of that input.

\section{Discussion}

It has long been appreciated that layer II of the PC contains morphologically distinctive types of glutamate-releasing principal neurons (Haberly, 1983; Haberly and Bower, 1984), broadly divisible into semilunar cells and superficial pyramidal cells (Neville and Haberly, 2004). Here, we extend earlier work by showing that SL- and SP-like cells are present in approximately equal numbers in layer II, and that they differ in their contributions to cortical microcircuits as follows: SL cells receive stronger afferent excitation from the olfactory bulb via the lateral olfactory tract, whereas SP cells receive stronger associational excitation from other principal neurons within the cortex. This conclusion holds both for unitary spike inputs and, less markedly, for trains of spike inputs. Thus, our findings suggest that SL and SP cells are specialized to provide two layers of synaptic processing (afferent and associational, respectively) within the piriform cortex. These results stress the importance of maintaining a distinction between these two cell types, rather than merging them into a homogeneous class of pyramidal cells (cf. Franks and Isaacson, 2005, 2006; Poo and Isaacson, 2009; Stettler and Axel, 2009; Stokes and Isaacson, 2010; Wilson, 2010).

\section{Measurement of synaptic strengths}

Our conclusions depend upon our ability to measure the strength of defined excitatory inputs onto identified neurons. Ideally, such experiments should be done using pair recordings in vivo, to correctly register all connections, including those that might be amputated in vitro. However, for reasons of feasibility, we used extracellular stimulation in acute brain slices. How reliable are our findings using such a system?

Many studies have confirmed that excitatory inputs to the PC are strictly laminated, enabling selective extracellular stimulation of aff and assn fibers (Stevens, 1969; Haberly and Price, 1978; Tang and Hasselmo, 1994). Moreover, we obtained identical results from both coronal and sagittal slices, suggesting that differential amputation of inputs is not a concern. In many of our experiments

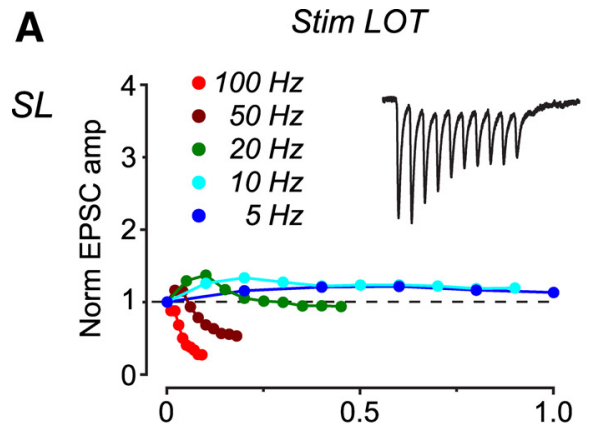

B Stim $l b$
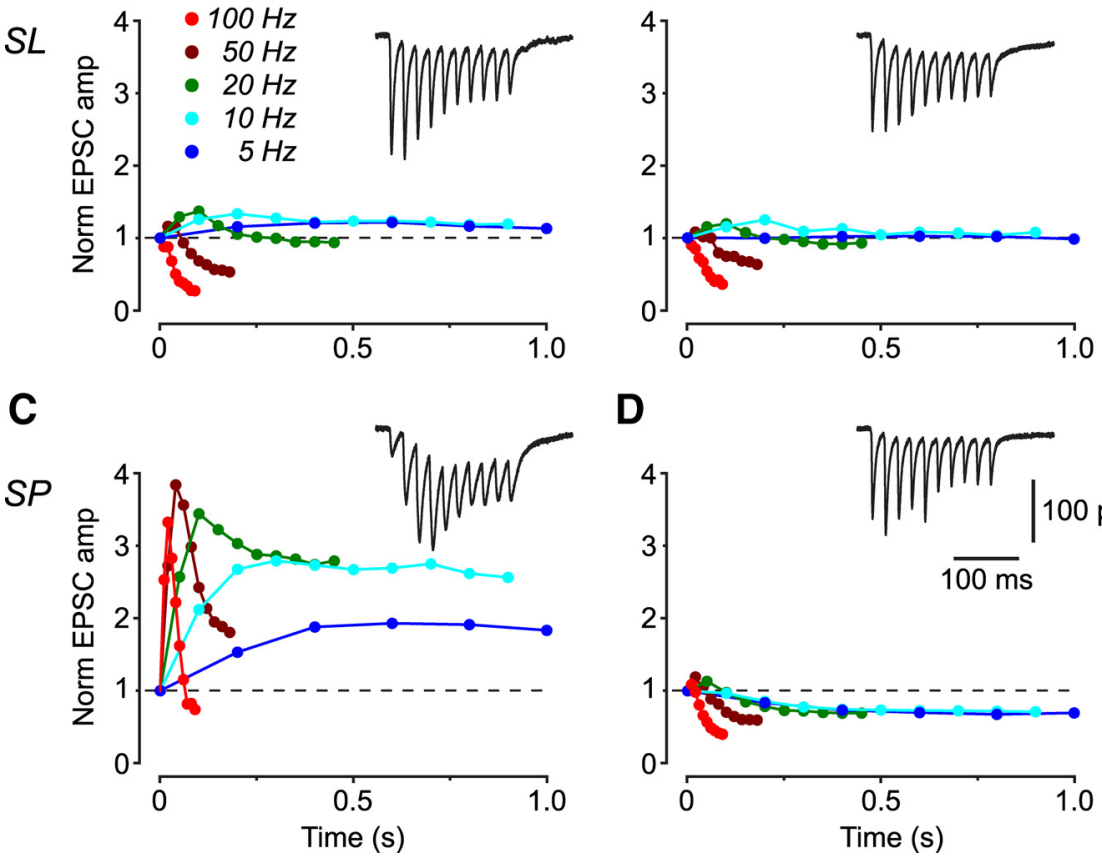

D

Figure 8. SL and SP cells show distinctive forms of short-term synaptic plasticity during trains of stimulation (Stim). $A-D$, Plots of normalized EPSC amplitude versus time during trains of 10 stimuli at different frequencies, recorded in SL cells $(A, B)$ and SP cells $(C, D)$ while stimulating the $L O T(A, C)$ or layer $\mathrm{Ib}(B, D)$. Amplitudes are normalized to the amplitude of the first EPSC in the train. Each panel shows averaged data from $n=6-9$ cells; error bars have been omitted for clarity. Insets show example EPSCS, each an average of 10 episodes recorded in a single cell ( $50 \mathrm{~Hz}$ stimulation; stimulus artifacts have been blanked). The scale bars in $\boldsymbol{D}$ refer to the insets in all panels. The bath solution contained $1 \mu \mathrm{m}$ DNQX and $50 \mu \mathrm{m}$ D-APV to minimize polysynaptic excitation (as well as $100 \mu \mathrm{m}$ picrotoxin to block $\mathrm{GABA}_{\mathrm{A}}$ receptors).
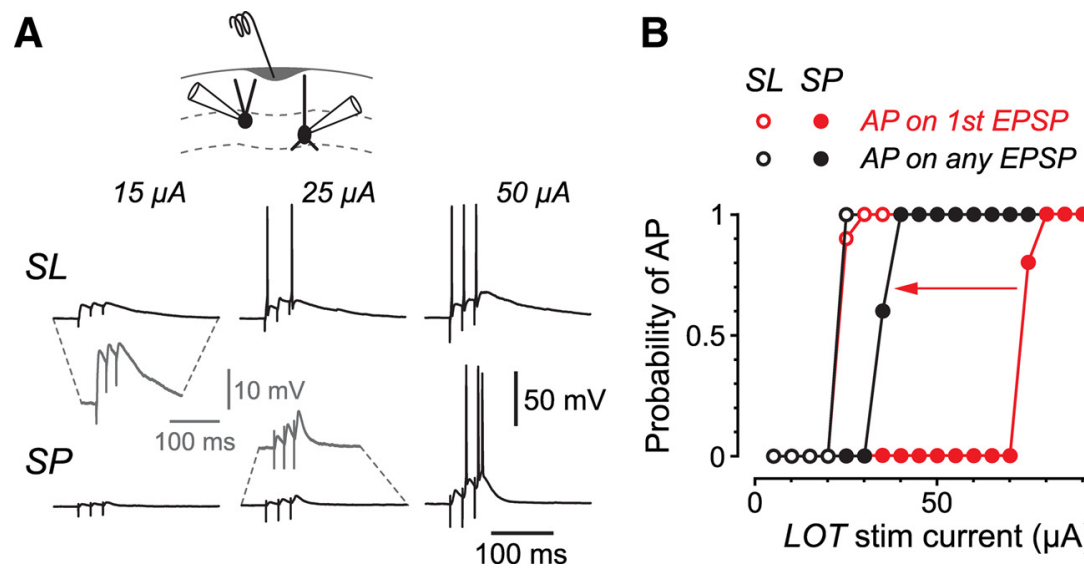

Figure 9. Trains of stimuli dynamically modify the differential synaptic input strengths onto SL and SP cells. $\boldsymbol{A}$, Simultaneous whole-cell current-clamp recordings from an SL cell (top row) and an SP cell (bottom row) while stimulating the LOT with a $50 \mathrm{~Hz}$ train of three stimuli at the indicated current strengths $(15,25,50 \mu \mathrm{A})$. Insets show, expanded, the synaptic facilitation present in the SP cell (bottom) but absent in the SL cell (top). The bath solution contained $100 \mu \mathrm{m}$ baclofen to block contamination by assn inputs. $\boldsymbol{B}$, Analysis of data from the cells in $\boldsymbol{A}$. Black lines and symbols plot the probability of firing at least one AP on any EPSP in the train versus stimulus (Stim) current strength. Red lines and symbols plot the probability of firing at least one AP on the first EPSP in the train versus stimulus strength (equivalent to the plots in Fig. $5 A_{2}$ ). By permitting APs to occur anywhere in the train, the responsiveness of the SP cell is shifted left (red arrow), closer to that of the SL cell. Similar results were obtained in 10 cell pairs.

we made dual recordings from SL and SP cells, allowing us to compare simultaneously the response of each cell to the same stimulus (Figs. 3, 5, 7, 9). The difference in assn input strengths between SL and SP cells was so striking (SP input $>15 \times$ SL input, on average) (Fig. 3) that systematic disparities in extracellular stimulation are unlikely to be an explanation. The difference in 
aff input strengths was less marked (SL input $\sim 2.4 \times$ SP input, on average, for single shocks). However, this finding was directly confirmed by minimal stimulation (Fig. 4), which is a method that is widely used to specifically excite single afferents and so is resistant to the usual concerns about bulk extracellular stimulation (Bekkers and Clements, 1999; Franks and Isaacson, 2006). These minimal stimulation experiments confirmed that aff excitation was, indeed, stronger in SL cells.

Finally, we provided two other pieces of evidence, less dependent on stimulus strength, in support of our conclusions. First, the tissue cut experiments (Fig. 6) drew upon information about synaptic and spike latencies, not stimulus strength, to confirm that SL cells were preferentially excited by aff input. Second, the hyperexcitability experiments (Fig. 7) used extracellular stimulation only to initiate delayed epileptiform activity, the properties of which were consistent with preferential excitation of SP cells by assn input. In summary, then, we have used an interlocking series of approaches to confirm our major findings.

\section{Mechanisms of differential input strengths}

What mechanisms could give rise to the differential input strengths we observe? Minimal stimulation of the LOT (Fig. $4 B$, left) shows that single aff fibers can generate surprisingly large EPSCs in SL cells $(>200 \mathrm{pA})$, but consistently produce small EPSCs in SP cells $(<50 \mathrm{pA})$. One possible explanation is that single aff axons make multiple synaptic contacts with the dendrites of SL cells, but only one or a few contacts with the dendrites of SP cells. There is some neuroanatomical evidence for this suggestion. The distal dendrites of SL cells (i.e., in layer Ia, where they are recipients of aff input) are studded with unusually large spines (Haberly, 1983). These structures are reminiscent of mossy fiber inputs on CA3 pyramidal neurons in the hippocampus, where clustered presynaptic release sites provide powerful single-fiber input (Hallermann et al., 2003). In a similar way, the anatomy of SL cells might be adapted for receiving strong afferent input from the olfactory bulb.

Minimal stimulation of layer Ib (Fig. $4 B$, right) shows that unitary assn inputs onto SL and SP cells are identical in size $(\sim 40$ $\mathrm{pA}$ ). Hence, the much larger responses to gross stimulation we observe in SP cells (Figs. 3B, 5B) cannot be due to stronger singlefiber inputs. Instead, it is likely that SP cells are simply the target of larger numbers of intracortical assn axons. This would be unsurprising, because SP cells, with their basal dendrites, seem optimized for sampling greater numbers of associational inputs (Fig. 1A) (Neville and Haberly, 2004). Furthermore, anatomical data suggest that SP cell dendrites are profusely spiny in associational layer Ib, which is a region where SL cell dendrites are comparatively aspiny (Haberly, 1983; Haberly and Behan, 1983).

\section{Implications for olfactory coding}

Franks and Isaacson (2006) have reported that pyramidal cells in layers II/III of the rat PC can receive powerful single-fiber afferent inputs (as well as weaker inputs) from the olfactory bulb, and that this finding has implications for the coding strategies used by the PC. Strong single-fiber input means that only a few coactive M/T cells in the olfactory bulb are required to bring a PC pyramidal cell to spike threshold, suggesting that odor stimulation is likely to produce broad and distributed firing in the PC (Franks and Isaacson, 2006). Indeed, such distributed activity has been reported in the PC using histological, electrophysiological, and imaging approaches (Wilson, 2001; Illig and Haberly, 2003; Rennaker et al., 2007; Poo and Isaacson, 2009; Stettler and Axel, 2009).
Here, we confirm the presence of strong and weak single-fiber afferent inputs to PC principal cells, but, in contrast to Franks and Isaacson (2006), we show that these two kinds of input are segregated onto two types of neuron, viz. SL and SP cells, respectively. Our findings are also consistent with those of Bathellier et al. (2009), who found little evidence of strong unitary inputs in SP cells. Interestingly, our distribution of unitary afferent strengths onto SL cells (Fig. $4 \mathrm{~B}$ ) closely resembles that obtained by Franks and Isaacson (2006) for their unspecified pyramidal cells (their Fig. 1D). In support of the idea that their dataset contained SL cells, their Figure 3 shows trains of EPSPs that do not strongly facilitate, consistent with the behavior of SL cells in response to aff inputs (Fig. 9A).

Our findings are still compatible with the idea that odor stimulation can produce broad and distributed firing in the PC (Franks and Isaacson, 2006), but with the refinement that this pattern of activity may be initiated in the SL cell layer (IIa). Presumably this excitation is then transmitted to and between the SP cells via their abundant assn inputs. These results suggest a simple two-layer model of excitation in the PC following odor stimulation, as follows: input from the olfactory bulb initially produces distributed firing in SL cells (layer IIa), followed rapidly by an additional pattern of distributed firing in SP cells (layer IIb). A further complication, however, is the presence of short-term synaptic facilitation that is restricted to aff inputs to SP cells (Fig. 8). As a result, the relative strength of inputs to SL and SP cells will alter during bursts of activity, enriching the dynamic features of olfactory coding (Mazor and Laurent, 2005).

The significance of our findings has several caveats. First, the distinction between SL and SP cells might not always be clear-cut; indeed, our cluster analysis (Fig. 1D) indicates some intermixing of SL- and SP-like cells in layer II, perhaps resulting in a more complex pattern of responses. Second, we have ignored the minority population of principal neurons that are found in layer III (Tseng and Haberly, 1989). Further work will be needed to incorporate these deep cells into models of cortical connectivity. Finally, most of our experiments were done in the presence of a $\mathrm{GABA}_{\mathrm{A}}$ receptor antagonist to block synaptic inhibition. Although this was appropriate for studying synaptic excitation in isolation, it is obvious that any model of the PC must include synaptic inhibition to achieve a realistic understanding of olfactory processing (Poo and Isaacson, 2009; Stokes and Isaacson, 2010; Suzuki and Bekkers, 2010a,b).

In summary, we have shown that the two main classes of glutamatergic neurons in the piriform cortex, SL cells and SP cells, engage differentially in afferent and associational circuits. These findings point to additional subtleties in the mechanisms used by the PC to process olfactory information.

\section{References}

Barnes DC, Hofacer RD, Zaman AR, Rennaker RL, Wilson DA (2008) Olfactory perceptual stability and discrimination. Nat Neurosci 11:1378-1380.

Bathellier B, Margrie TW, Larkum ME (2009) Properties of piriform cortex pyramidal cell dendrites: implications for olfactory circuit design. J Neurosci 29:12641-12652.

Bekkers JM, Clements JD (1999) Quantal amplitude and quantal variance of strontium-induced asynchronous EPSCs in rat dentate granule neurons. J Physiol 516:227-248.

Bower JM, Haberly LB (1986) Facilitating and nonfacilitating synapses on pyramidal cells: a correlation between physiology and morphology. Proc Natl Acad Sci U S A 83:1115-1119.

Cang J, Isaacson JS (2003) In vivo whole-cell recording of odor-evoked synaptic transmission in the rat olfactory bulb. J Neurosci 23:4108-4116.

Franks KM, Isaacson JS (2005) Synapse-specific downregulation of NMDA 
receptors by early experience: A critical period for plasticity of sensory input to olfactory cortex. Neuron 47:101-114.

Franks KM, Isaacson JS (2006) Strong single-fiber sensory inputs to olfactory cortex: Implications for olfactory coding. Neuron 49:357-363.

Haberly LB (1983) Structure of the piriform cortex of the opossum. I. Description of neuron types with Golgi methods. J Comp Neurol 213:163-187.

Haberly L, Behan M (1983) Structure of the piriform cortex of the opossum. III. Ultrastructural characterization of synaptic terminals of association and olfactory bulb afferent fibers. J Comp Neurol 219:448-460.

Haberly LB, Bower JM (1984) Analysis of association fiber system in piriform cortex with intracellular recording and staining techniques. J Neurophysiol 51:90-112.

Haberly LB, Price JL (1978) Association and commissural fiber systems of the olfactory cortex of the rat. I. Systems originating in the piriform cortex and adjacent areas. J Comp Neurol 178:711-740.

Hallermann S, Pawlu C, Jonas P, Heckmann M (2003) A large pool of releasable vesicles in a cortical glutamatergic synapse. Proc Natl Acad Sci U S A 100:8975-8980.

Hasselmo ME, Bower JM (1990) Afferent and association fiber differences in short-term potentiation in piriform (olfactory) cortex of the rat. J Neurophysiol 64:179-190.

Illig KR, Haberly LB (2003) Odor-evoked activity is spatially distributed in piriform cortex. J Comp Neurol 457:361-373.

Isaacson JS (2010) Odor representations in mammalian cortical circuits. Curr Opin Neurobiol 20:328-331.

Johenning FW, Beed PS, Trimbuch T, Bendels MH, Winterer J, Schmitz D (2009) Dendritic compartment and neuronal output mode determine pathway-specific long-term potentiation in the piriform cortex. J Neurosci 29:13649-13661.

Laurent G (2002) Olfactory network dynamics and the coding of multidimensional signals. Nat Rev Neurosci 3:884-895.

Mazor O, Laurent G (2005) Transient dynamics versus fixed points in odor representations by locust antennal lobe projection neurons. Neuron 48:661-673.

Neville KR, Haberly LB (2004) Olfactory cortex. In: The synaptic organiza- tion of the brain, Ed 5 (Shepherd GM, ed), pp 415-454. New York: Oxford UP.

Poo C, Isaacson JS (2007) An early critical period for long-term plasticity and structural modification of sensory synapses in olfactory cortex. J Neurosci 27:7553-7558.

Poo C, Isaacson JS (2009) Odor representations in olfactory cortex: "sparse" coding, global inhibition, and oscillations. Neuron 62:850-861.

Rennaker RL, Chen CF, Ruyle AM, Sloan AM, Wilson DA (2007) Spatial and temporal distribution of odorant-evoked activity in the piriform cortex. J Neurosci 27:1534-1542.

Stettler DD, Axel R (2009) Representations of odor in the piriform cortex. Neuron 63:854-864.

Stevens CF (1969) Structure of cat frontal olfactory cortex. J Neurophysiol 32:184-192.

Stokes CC, Isaacson JS (2010) From dendrite to soma: dynamic routing of inhibition by complementary interneuron microcircuits in olfactory cortex. Neuron 67:452-465.

Suzuki N, Bekkers JM (2006) Neural coding by two classes of principal cells in the mouse piriform cortex. J Neurosci 26:11938-11947.

Suzuki N, Bekkers JM (2010a) Inhibitory neurons in the anterior piriform cortex of the mouse: Classification using molecular markers. J Comp Neurol 518:1670-1687.

Suzuki N, Bekkers JM (2010b) Distinctive classes of GABAergic interneurons provide layer-specific phasic inhibition in the anterior piriform cortex. Cereb Cortex 20:2971-2984.

Tang AC, Hasselmo ME (1994) Selective suppression of intrinsic but not afferent fiber synaptic transmission by baclofen in the piriform (olfactory) cortex. Brain Res 659:75-81.

Tseng GF, Haberly LB (1989) Deep neurons in piriform cortex. I. Morphology and synaptically evoked responses including a unique high-amplitude paired shock facilitation. J Neurophysiol 62:369-385.

Wilson DA (2001) Receptive fields in the rat piriform cortex. Chem Senses 26:577-584.

Wilson DA (2010) Single-unit activity in piriform cortex during slow-wave state is shaped by recent odor experience. J Neurosci 30:1760-1765.

Young A, Sun QQ (2009) GABAergic inhibitory interneurons in the posterior piriform cortex of the GAD67-GFP mouse. Cereb Cortex 19:3011-3029. 